\title{
Concepções de saúde, doença e cuidado em Primeiras estórias, de Guimarães Rosa
}

\section{Conceptions of health, illness and care in Guimarães Rosa's Primeiras estórias}

\author{
Fabio Scorsolini-Comin ${ }^{\mathrm{a}}$ \\ anniversidade de São Paulo. Escola de Enfermagem de Ribeirão \\ Preto. Departamento de Enfermagem Psiquiátrica e Ciências \\ Humanas. Ribeirão Preto, SP, Brasil. \\ E-mail: fabio.scorsoliniळusp.br

\section{Isabella Alcântara Figueiredo ${ }^{b}$} \\ bUniversidade Federal do Triângulo Mineiro. Departamento de \\ Psicologia. Uberaba, MG, Brasil. \\ E-mail: isabella.isaaøhotmail.com
}

\section{Resumo}

A partir da antropologia da saúde e da psiquiatria transcultural, este estudo teórico analisou as concepções de saúde e doença presentes em três contos que compõem a obra Primeiras estórias (1962), de Guimarães Rosa: "Sorôco, sua mãe, sua filha", "A menina de lá" e "A terceira margem do rio". Observou-se uma diversidade de conceitos e sentimentos diante das questões de saúde mental apresentadas nos contos, como: falta de compreensão, marginalização, pressão social para a institucionalização, estereotipação, desumanização, isolamento físico e mental, sentimentos de medo e culpa, tentativa de aceitação e mistificação. Tendo como norte a indissociável relação entre autor, obra, público e condições sociais, tais elementos presentes nos contos podem ser importantes para se revisitar histórica e culturalmente as práticas dentro dos ambientes de cuidado em saúde mental, em busca de uma atenção mais humanizada e que combata a violência nesse contexto, favorecendo uma visão que, de fato, ultrapasse o modelo biomédico centralizado na patologia e promova novos sentidos para a saúde e o adoecer.

Palavras-chave: Antropologia da Saúde; Processo Saúde-Doença; Guimarães Rosa; Saúde Mental.

\section{Correspondência}




\section{Abstract}

Starting from anthropology of health and crossculturalpsychiatry, this theoretical studyanalyzed the conceptions of health and illness present in three short stories of the book Primeiras estórias (1962) written by Guimarães Rosa: "Sorôco, sua mãe, sua filha", "A menina de lá" and "A terceira margem do rio" (in Portuguese). A diversity of concepts and feelings related to mental health issues was noticed in these short stories, such as: lack of comprehension, marginalization, social pressure for institutionalization, stereotyping, dehumanization, mental and physical isolation, feelings of fear and guilt, and acceptance and mystification attempts. Considering the indissociable relation between author, work, public, and social conditions, such elements present in the short stories can be important to revisit, historically and culturally, practices inside mental health care institutions when searching for a more humanized care that combat the violence in this context, favoring a view that indeed surpasses the biomedical model centralized in pathologies and promotes new meanings for health and illness.

Keywords: Anthropology of Health; Health-Illness Process; Guimarães Rosa; Mental Health.
Os conceitos de saúde e de doença foram construídos e modificados diversas vezes ao longo da história do mundo. São definições que se transformam continuamente, estando intimamente relacionadas aos contextos histórico, geográfico, político, social, econômico e cultural de uma sociedade ou comunidade. Essas definições envolvem desde ações de políticas públicas de um determinado Estado a comportamentos da população diante das questões de saúde apresentadas em seu ambiente, possibilitando diversos manejos e formas de cuidado.

Em meio a tantas tentativas de se pensar em um conceito, a Organização Mundial da Saúde (OMS) propôs uma definição de saúde que considerava ser universalmente aceita. Divulgada em 1948, definia que saúde "é o estado do mais completo bem-estar físico, mental e social e não apenas a ausência de enfermidade”. Tal conceito sofreu muitos questionamentos devido a sua amplitude e, nessa época, até surgiram muitas outras concepções diferentes por parte dos críticos (Scliar, 2007). Em 1988, a OMS incluiu a dimensão espiritual no conceito de saúde, entendendo-a como relacionada aos significados e sentidos da vida, emoções e convicções de natureza não material, não se limitando a um tipo específico de crença ou prática religiosa (Alves, Assis, 2015; Gomes, Farina, Forno, 2014; Oliveira, Junges, 2012; Volcan et al., 2003).

Já a noção de doença possui diferentes sentidos na língua inglesa, possibilitando uma compreensão semântica mais apurada e que amplia a visão mais linear, por vezes priorizada em modelos mais tradicionais, como no biomédico. A doença (disease) recupera a dimensão da fisiopatologia, enquanto a experiência da doença (illness) inclui as dimensões psicossociais do adoecer. Em outras palavras, a patologia é algo que um órgão tem (disease), enquanto a perturbação é algo que uma pessoa tem (illness). Adoecer é sempre um processo social que envolve outras pessoas além do paciente/cliente/ usuário, em uma compreensão mais holística. Essa diferenciação entre os termos tem sido bastante explorada no contexto da antropologia da saúde (Helman, 2006; Kleinman, 1988; Nakamura, Martin, Santos, 2009).

A partir desses conceitos, para compreender como se dão os processos de saúde e doença, faz-se 
necessário estudar cada sociedade e sua cultura separadamente, pois é a cultura que modela o que se entende, sente e pensa sobre o "estar doente", não se limitando somente a alterações biológicas. A cultura pode ser entendida como a soma de um complexo de fatores que são representados por meio de crenças, comportamentos, valores, leis, símbolos, normatizações e práticas de uma sociedade. É um conjunto de princípios que se aprende, compartilha e padroniza no grupo do qual o indivíduo cresce, sendo que tais princípios mostram como ele deve ver, vivenciar, se comportar e reagir ao que se apresenta a ele no mundo. Para Geertz (1978), funciona como uma "lente" que codifica o que o indivíduo tem contato, permitindo que tenha a capacidade de perceber o mundo e aprenda a viver nele, é o que possibilita criar para si uma representação da realidade, além ser uma forma de controle dos comportamentos e vivências dos indivíduos (Campos, 2017; Helman, 20o6; Kleinman, 1988; Langdon, Wiik, 2010; Oliveira, 2002).

Além da cultura que engloba toda uma sociedade, podem existir, dentro dessa mesma sociedade, outros tipos de culturas. Estas podem se diferenciar pela linguagem, por modos de vestir, pelo padrão de alimentação, por moradia, comportamentos, crenças, ideologias, entre outros. Apesar de fazerem parte de um único todo, a maioria das sociedades possui alguma forma de estratificação, seja ela por razões econômicas, sociais (ricos e poderosos, pobres e desprovidos - cada um herdará sua própria visão cultural), seja ela por questões de gênero, etnia, orientação sexual, pois cada variante pode obedecer a normas e expectativas diferentes em uma mesma sociedade (Helman, 2006; Langdon, Wiik, 2010).

A cultura da sociedade na qual a pessoa nasce ou vive não é a única a influenciar as crenças e comportamentos relacionados à saúde. Helman (2006) introduz mais quatro fatores: individuais, educacionais, socioeconômicos e ambientais. Em determinado contexto as pessoas podem agir de maneira mais tendenciosa em relação à sua cultura, já em outro, se comportar de acordo com a situação econômica na qual vivem, ou então conforme aprenderam a acreditar, de acordo com sua educação. Apesar de estarem englobados dentro de uma cultura maior e de carregarem muito dos seus conceitos e valores, a depender de cada fator, os indivíduos formarão um grupo à parte em que constituirão seus próprios conceitos, normas, regras e organização social.

A antropologia admite que existam características universais de determinados fatores biológicos da saúde e doença, porém estas são experiências que não somente envolvem questões de alteração biológica no corpo, mas também questões culturais. Estas irão refletir nos modos de cada ator social (indivíduo, família, comunidade, agentes de saúde etc.) que esteja envolvido no processo saúdedoença entender, vivenciar, reagir e significar suas experiências (Amadigi et al., 2009; Campos, 2017; Oliveira, 2002). A antropologia possui uma área específica, chamada antropologia da saúde, que estuda justamente como as pessoas pertencentes a uma determinada sociedade e cultura experienciam, produzem, entendem e reagem às questões de saúde e doença. Além disso, investiga os tipos de tratamento que as pessoas buscam e como todas essas vivências e crenças afetam o organismo humano (em sua totalidade - biológico, psicológico e social) e todo o resto que o envolve (Helman, 2006; Oliveira, 2002).

Autores da antropologia da saúde, como Helman (2006) e Kleinman (1988), destacam que, ao se pensar a saúde de um indivíduo, deve-se considerar, além da cultura de sua sociedade, que ele pertence a um grupo e está inserido em um contexto particular. Um fator analisado dentro desse contexto pode ser o socioeconômico. Por exemplo, uma pessoa que não possui um padrão alimentar considerado saudável, que não procura atendimento de saúde quando adoece e vive uma situação de pobreza, não toma todas as providências necessárias porque isso faz parte da sua cultura, mas sim porque o fator financeiro pode limitá-la de diversas maneiras. É preciso também entender os tipos de assistência aos quais essas pessoas têm contato, o que significa compreender a forma como são reconhecidos os doentes, como apresentam as suas doenças, quais pessoas da rede de assistência de saúde de sua sociedade elas buscam e as formas de manejo destes frente às questões que se apresentam (Helman, 2006; Kleinman,1988; Kleinman, Eisenberg, Good, 1978).

Kleinman (1988), por meio de seu sistema de atenção à saúde, explica que a doença, a reação diante 
dela, a pessoa que dela padece, os indivíduos que a tratam e as instituições sociais envolvidas estão interconectadas sistematicamente. É um modelo criado para se compreender a totalidade dessa inter-relação, pensando que saúde e doença devem ser estudadas em seu contexto global, evitando as análises com olhar etnocêntrico. Ele sugere três subsistemas de cuidado à saúde: o informal, que é o familiar, a expressão do senso comum, podendo se compor pela família, o próprio indivíduo, rede social e a comunidade próxima; o popular (folk), caracterizado por especialistas de cura não profissional, como curandeiros, padres, pais ou mães de santo, benzedeiras (Marin, Scorsolini-Comin, 2017); e o profissional, que seriam os profissionais de cura com aprendizado formal. Esses subsistemas são utilizados pelos indivíduos não de maneiras excludentes, mas sim sobrepostas, complementares (Amadigi et al., 2009; Coelho; Almeida Filho, 2002; Langdon; Wiik, 2010; Oliveira, 1998).

A psiquiatria transcultural, para Helman (2006), é uma área de estudo da antropologia da saúde que investiga e compara a saúde e o sofrimento mental em diferentes culturas, preocupando-se mais com as dimensões psicológicas, comportamentais e socioculturais desse sofrimento do que com sua dimensão orgânica, mas isso não quer dizer que a desconsidere. $\mathrm{O}$ autor explica que "os antropólogos estão mais interessados em saber de que modo os fatores culturais influenciam o comportamento e as percepções do paciente, o conteúdo das alucinações ou delírios e a conduta de terceiros em relação ao paciente" (Helman, 2006, p. 222).

Kleinman (1988) fez muitas críticas ao modelo psiquiátrico praticado na época. Tal modelo considerava haver uma universalidade dos padrões de doença, que analisava os sofrimentos mentais em ambientes culturais diferentes tendo como referência as crenças e vivências ocidentais. Configurava-se no que ele chama de "falácia de categorização", algo que está implícito nos modelos biomédicos, com suas tentativas de encaixar uma mesma estrutura diagnóstica para diferentes culturas. Para o autor, o ideal seria que a "medicina fosse vista como uma profissão baseada em três fontes de conhecimento: a ciência biológica, a ciência clínica e a ciência social” (Kleinman, 1988, p. 162, tradução livre). Helman (2006) também discute essa ideia ao conceituar três tipos de abordagens utilizadas no estudo das questões psiquiátricas: a biológica, que foi o alvo das críticas de Kleinman; a da rotulação social, que vê o sofrimento mental como um acontecimento somente social ao invés de biológico; e a combinada, que utiliza elementos das duas abordagens anteriores, com a qual os antropólogos da saúde mais se identificam.

O modo como os processos de saúde e doença são compreendidos em dada sociedade e atravessam os diversos tempos históricos pode ser acessado por meio de documentos que retratam o ethos de cada período, suas crenças, práticas e concepções que se articulam, por exemplo, na maneira como as pessoas adoecidas são cuidadas ou não, quais tipos de tratamentos são colocados em vigor e como a cura é concebida em cada cultura. A literatura é uma importante fonte de dados, justamente por colocar em destaque os costumes das diversas épocas, apresentando, por meio das narrativas de seus personagens, por vezes fictícios, elementos que configuram o que podemos compreender como próprio a cada período histórico e a cada contexto específico (Scorsolini-Comin; Santos, 2012). Assim, essas obras também contribuem para que determinados conceitos sejam apreendidos de modo contextualizado e integrados à sociedade de referência, como explicitado a seguir, tomando por base a produção literária de Guimarães Rosa.

\section{A literatura de Guimarães Rosa e os processos de saúde e doença}

João Guimarães Rosa é um dos autores brasileiros de maior renome, sendo farta a literatura científica interessada nos mais diversos elementos da sua prosa (Arroyo, 1984; Leonel, 1985; Roncari, 2004), além do destaque para o processo de construção de um léxico próprio que inclui elementos sociais e culturais atravessando expressivamente a linguagem e a construção das palavras (Martins, 2008). A escrita rosiana tem a forte presença das falas orais, apresenta, muitas vezes, a ressignificação da linguagem pelo recurso do estranhamento, traduzindo-se em um estilo único. Em suas histórias, abrange os mistérios da existência humana em suas 
mais variadas formas. A obra de Guimarães Rosa já foi alvo de diversos estudos, entre eles alguns do campo da ciência psicológica (Belo, 1999; Coutinho, 1998; Leite, 2002; Montagna, 2011; Oliveira, 2015; Scorsolini-Comin, 2010; Scorsolini-Comin, Santos, 2014). Desse modo, compreende-se que a obra de Guimarães Rosa é emblemática tanto para a literatura brasileira como para a ciência interessada no diálogo com a obra de arte como representativa de uma época e também como documento histórico de determinada sociedade.

O exercício de empregar a literatura como campo de estudo na interface com a psicologia e a sociologia tem sido conduzido por muitos pesquisadores interessados em análises que ultrapassem os aspectos puramente linguísticos, considerando condições de produção que entrelaçam elementos constitutivos como autor, obra e público (Candido, 2010; Leite, 2002). Nessa perspectiva, abarcamse as condições sociais e psicológicas capazes de explicar posicionamentos, deslocamentos e tensionamentos expressos no texto. Na interface com a saúde, Rocha (2002) e Belo (1999) destacam, por exemplo, que a prosa rosiana pode apontar para elementos importantes, como os de morte e loucura, circunscrevendo como tais aspectos cravam-se - mais do que nos enredos - nas pessoas e nos contextos representados nos personagens e nas narrativas, em fértil diálogo com a medicina e a cultura.

As narrativas e personagens dos contos escolhidos para análise neste estudo estão no livro Primeiras estórias, originalmente publicado em 1962 e composto por 21 contos. Um traço que emerge nessa produção é que as narrativas ficcionais em tela corporificam a necessidade de uma abordagem cultural do adoecimento, encontrando na literatura uma representação das noções de saúde e doença vigentes em nossa sociedade (Leite, 2002; Montagna, 2011; Rosenbaum, 2008). Mais do que isso, as "estórias" rosianas possibilitam uma leitura para além da mera interpretação que, por vezes, sugere a justaposição de fragmentos, como se o percurso analítico fosse o apontamento de determinados elementos - no caso, os de saúde e adoecimento no texto literário. Essa identificação é importante, mas o convite é para que a obra seja compreendida do ponto de vista social, dependendo tanto da ação de fatores do meio como de efeitos práticos, "modificando a sua conduta e concepção de mundo, ou reforçando neles o sentimento dos valores sociais" (Candido, 2010, p. 30). A partir do panorama exposto, o objetivo principal deste estudo teórico é descrever as concepções de saúde e doença nos contos que compõem a coletânea Primeiras estórias, de João Guimarães Rosa.

\section{Método}

Este estudo foi desenvolvido na modalidade documental. Os contos do livro Primeiras estórias selecionados para discussão - "Sorôco, sua mãe, sua filha”, "A menina de lá" e "A terceira margem do rio" - constituem o corpus analítico. Tais contos foram selecionados por trazerem à baila narrativas nas quais os conceitos de saúde e doença emergem de modo mais significativo, permitindo uma análise contextual representativa da época em que foram escritos, bem como da sociedade na qual viveu seu autor. Utilizaram-se para a análise e discussão dois teóricos de referência no campo da antropologia da saúde: Cecil G. Helman e Arthur Kleinman.

Em termos do percurso analítico adotado para este estudo, recupera-se que, na interpretação de uma obra literária, é fundamental compreender de modo integrado sua produção (feitura) e sua repercussão, haja vista que a arte é um "sistema simbólico de comunicação inter-humana” (Candido, 2010, p. 31). Assim, não se pode separar o modo como uma obra foi produzida, tomando por base aspectos da biografia do autor, do seu tempo e de seus posicionamentos, da forma como ela mesma foi divulgada, recebida, lida e promovida pelo público, representando, aqui, a sociedade que situa tal produção dentro de determinado repertório. Tomando por base essas considerações, a fim de explorar a tríade analítica proposta por Candido (2010) - autor, obra e público -, esses elementos serão delineados na seção de Resultados e discussão. Posteriormente, os contos serão brevemente sumarizados e interpretados tendo em vista os objetivos deste trabalho e amparados na literatura do campo da antropologia da saúde. Por fim, será proposta a integração das narrativas de saúde, adoecimento e cuidado a partir das discussões apresentadas no texto. 


\section{Resultados e discussão}

\section{Autor, obra e público: Guimarães Rosa e as Primeiras estórias}

João Guimarães Rosa, nascido em Cordisburgo (MG) em 1908, ingressou aos 17 anos na faculdade de medicina. Durante seus estudos na então Faculdade de Medicina de Minas Gerais, chamou atenção de seus colegas e professores para uma prática médica mais humanista. Ao longo de sua atuação como médico, demonstrou ser um profissional muito atento aos seus pacientes e, inclusive, teve convivência próxima e harmoniosa com receitadores e raizeiros no decorrer de sua atuação em Itaguara (MG). Em 1933, Rosa foi transferido para Barbacena (MG), na condição de Oficial Médico do $9^{\circ}$ Batalhão de Infantaria, descobrindo, nesse lugar, que não tinha vocação para a medicina. Buscou então a carreira da diplomacia e, paralelamente a ela, se entregou também à carreira literária (Rocha, 2002).

Embora sua formação médica possa ser considerada na análise, notadamente por explorarmos os processos de saúde e doença que são bases desse fazer, não se trata, pois, de um emprego automático e que possivelmente nos conduziria a uma incorporação acrítica de sua biografia na tentativa de explicar a obra e sua repercussão, bem como o possível destaque para as questões de saúde e doença. A costura de elementos biográficos com a obra em questão deve nos alertar para uma análise mais densa, não determinista. Assim, ao considerar a dimensão do autor, é importante que ela seja avaliada tanto na interação com os elementos da própria obra, como enfatizado nesta discussão, quanto no modo como a obra foi e tem sido reconhecida pela crítica literária.

Segundo Roncari (2004), Guimarães Rosa utiliza três fontes principais na estruturação de sua escrita: (1) empírica, recorrendo a experiências próprias, inclusive de trânsito por diferentes regiões do país, seus costumes e tradições; (2) mítica e universal, por meio de sua reverência e referência a obras clássicas da literatura; (3) nacional, empregando elementos da literatura brasileira e também de estudos sobre o Brasil e o povo brasileiro. Tais fontes estariam presentes em toda sua produção, havendo predomínio de um elemento ou outro a depender da obra analisada. Essas três fontes principais seriam responsáveis, ainda de acordo com Roncari, por três camadas do texto, a saber: (1) a exploração do universo brasileiro ligado a signos como o sertão e o jagunço, por exemplo; (2) exploração da dimensão mítica e simbólica, a partir de uma expressiva erudição; (3) exploração da vida político-institucional brasileira.

Nos contos escolhidos para este estudo, os personagens demonstram seus sofrimentos mentais e como a comunidade e a cultura de cada lugar reagem a eles, inclusive em termos institucionais, recuperando histórias e personagens que representam a figura do brasileiro interiorano, sertanejo, assolado pela crescente urbanização, convidado constantemente a atualizar o modo como os elementos da vida cotidiana e cultural vão sendo mesclados a "avanços” tecnológicos, incidindo, como priorizado neste trabalho, nos processos de compreensão do que é saúde, doença e cuidado. Os contos revelam cenários de cuidado em regiões nas quais crenças religiosas e mágicas circulam no espaço discursivo e contribuem para a costura de discursos sobre saúde mental, tanto oferecendo explicações e justificativas como dando suporte ao estabelecimento de formas de cuidado e acolhimento, em diálogo com sistemas mais formais (Helman, 2006; Kleinman, 1988). Esses elementos serão delineados de modo mais pormenorizado na análise de cada conto.

\section{Primeiro conto: "Sorôco, sua mãe, sua filha"}

O conto se concentra na história de Sorôco, um homem viúvo, que está levando sua mãe e sua filha - as únicas parentes com que tinha contato para embarcarem em um vagão e serem levadas ao hospital psiquiátrico na cidade de Barbacena (MG). Existe uma atmosfera estabelecida pelos moradores da cidade de pressão, curiosidade, pena, sensação de alívio (por entenderem que seria melhor para Sorôco ficar sem a mãe e a filha), pensamentos sobre a condição de doença dessas mulheres; tudo isso enquanto acompanham a certa distância o trajeto de Sorôco. Após o embarque das mulheres, o homem 
começa a voltar para casa e é tomado por imensa tristeza e solidão, entoando o canto que mais cedo a filha e a mãe também cantaram durante o trajeto até o trem. Nesse momento, a comunidade sente imensa compaixão por Sorôco, decidindo se unir a ele no canto, o acompanhando até em casa.

Pode-se observar, desde o primeiro momento do conto, quando é descrita a forma como serão transportadas aquelas mulheres, o caráter de desumanização com que eram vistas e seriam tratadas. Sobre o carro no qual seriam transportadas as personagens, o narrador conta: "a gente reparando notava as diferenças. Assim repartido em dois, num dos cômodos as janelas sendo de grades, feito as de cadeia, para os presos" (Rosa, 2008, p. 19). Desde o início da história do mundo, a loucura, quando identificada, era entendida como outra dimensão de homem. Seu presente é marcado por uma história em que já foi considerada uma manifestação divina, mas também - e muito mais - foi marcada pela exclusão, marginalização, violência, com que os indivíduos foram tirados de sua condição de humano (Garcia Neto, Tauro, 2015). Tais crenças e visões (divino, diabólico, desumano) refletem no tratamento dado por parte de toda sociedade a esses indivíduos (Helman, 20o6; Kleinman, 1988). Na situação do conto, o vagão com um cômodo de janela com grades representa uma violência institucional, que mostra a atitude de encarceramento e isolamento mediante a manifestação da loucura. Rosa (2008, p. 20) faz, ainda, uma comparação do vagão que transportaria as mulheres a um navio: "O carro lembrava um canoão no seco, navio". Essa imagem remete à "Nau dos loucos", Narrenschiff, citada por Foucault (2010). Essa nau, que existiu na metade do século XV, tinha a função de transportar os considerados insanos de uma cidade para outra e caracterizava a postura da sociedade europeia da época, de negligência e discriminação diante do que se relacionava à saúde mental. Foucault (2010, p. 11-12) explica que "confiar o louco aos marinheiros é com certeza evitar que ele ficasse vagando indefinidamente entre os muros da cidade, é ter a certeza de que ele irá para longe, é torná-lo prisioneiro de sua própria partida”.

Além disso, nota-se que o serviço de atenção à saúde era totalmente baseado no modelo biomédico, na abordagem biológica conceituada por Helman
(2006), em que considera-se que as categorias diagnósticas do modelo psiquiátrico do ocidente seriam aplicáveis universalmente. "Parecia coisa de invento de muita distância [o vagão], sem piedade nenhuma, e que a gente não pudesse imaginar direito nem se acostumar de ver, e não sendo de ninguém” (Rosa, 2008, p. 20). Dizer que o vagão não pertencia a ninguém ilustra o caráter impessoal, generalista, de uma rede que era intocável, impossível de ser questionada e que também não achava necessário entrar em contato com a realidade do indivíduo, sendo totalmente alheia de sua cultura e subjetividade.

"Iam servir para levar duas mulheres, para longe, para sempre” (Rosa, 2008, p. 20). Entendese com essa afirmação que quem ia para lá não mais voltava. O Centro Psiquiátrico de Barbacena, informalmente conhecido como "O Colônia", foi inaugurado em 1903 e continuou em atividade até por volta de 1980. O hospital era composto não só por pessoas que padeciam de algum sofrimento mental, mas também por indivíduos que, de alguma forma, se desviavam da norma social da época (por exemplo: militantes políticos, homossexuais, mendigos e negros). A mãe e a filha de Sorôco, além serem estigmatizadas pela cultura por seu estado de saúde mental, partiam de mais dois lugares sociais excludentes: o de gênero - ambas eram mulheres - e o econômico - eram pobres; ou seja, eram mulheres, "loucas" e pobres, uma combinação indesejável para a sociedade. Após a internação no hospital de Barbacena, os indivíduos perdiam sua identidade, sua história, o vínculo familiar e social, consequência do isolamento e da exclusão impostos pela instituição. "O Colônia" foi considerado o maior manicômio brasileiro e também o lugar onde, com o assentimento do Estado, da Igreja Católica, da comunidade médica e da sociedade, ocorreu o que foi considerado por muitos o "Holocausto brasileiro", em que as pessoas eram vítimas de tortura, agressão física e psicológica, tendo sido registradas mais de 60 mil mortes de vítimas da violências e negligência sofridas dentro da instituição (Castilho, Sant'anna, Alonso, 2017).

Algo bem aparente no conto é a forma como a sociedade impunha suas regras para Sorôco e sua família: "Todos ficavam de parte, a chusma de gente 
não querendo afirmar as vistas, por causa daqueles transmodos e despropósitos, de fazer risos, e por conta de Sorôco - para não parecer pouco caso" (Rosa, 2008, p. 21). As pessoas da comunidade estavam distantes, mas vigilantes, observando se Sorôco obedeceria às regras estabelecidas por elas. A regra de que a "loucura" deveria ser institucionalizada, aprisionada e isolada do convívio social. A visão da comunidade sobre o indivíduo influenciará na forma como será realizado seu tratamento, o que é revelado pelo olhar de distanciamento que as pessoas tinham em relação às "loucas" (Almeida Filho, Coelho, Peres, 1999; Coelho, Almeida Filho, 2002; Kleinman, 1988; Oliveira, 1998). Existe a percepção de que um vagão ter grades e o fato de ele estar "do lado do curral de embarque de bois" (Rosa, 2008, p. 19) não era algo apropriado; no entanto, como eram "loucas" que seriam transportadas, havia certo assentimento, as coisas eram assim mesmo. Isso fica evidente no trecho: "O que os outros se diziam: que Sorôco tinha tido muita paciência. Sendo que não ia sentir falta dessas transtornadas pobrezinhas, era até um alívio. Isso não tinha cura, elas não iam voltar, nunca mais” (Rosa, 2008, p. 21). A forma desumanizada como as personagens eram vistas por sua comunidade era somente um reflexo das concepções de saúde e doença da sociedade em geral daquela época. No conto não são apresentados seus nomes, não se sabe seus gostos, nada é dito sobre o sentimento delas. Rosa (2008, p. 21) chega a descrever: "sem tanto que diferentes, elas se assemelhavam" - se assemelhavam por ambas se destoarem da norma, porém não lhes era permitido terem suas singularidades.

A maneira com que o comportamento de uma pessoa é percebido por sua própria comunidade é um ponto importante a ser considerado ao se fazer um diagnóstico no olhar da psiquiatria transcultural. Esta considera essencial analisar cuidadosamente os aspectos da cultura e subjetividade ao diagnosticar um indivíduo, tomando cuidado para que os fatores biológicos não escondam ou se sobreponham aos problemas sociais presentes na sociedade, que podem inclusive ser o motivo do adoecimento mental ou, no mínimo, da piora deste; e até ser a causa dos sintomas físicos naquele indivíduo, sendo adquiridos através da somatização (Helman, 20o6; Kleinman, 1988).
Outro ponto abordado no conto é a consequência da perda, a vivência do luto de Sorôco e como isso foi percebido por sua comunidade. Sorôco era viúvo, só tinha uma filha e a mãe já com mais de 70 anos; despedia-se das únicas pessoas de sua família com quem tinha contato. Enviá-las para o hospital de Barbacena era o mesmo que saber que nunca mais as veriam, era como perdê-las para a morte. "Era uma tristeza, parecia enterro" (Rosa, 2008, p. 21). Para Sorôco, diferentemente de sua comunidade, aquelas mulheres ocupavam outro lugar dentro de sua vida, para além da cultura que os envolvia: eram sua mãe e sua filha. Quem seria agora Sorôco, sem suas referências, sem sua base e única herança familiar? Foi como se tivesse ficado sem passado e futuro. Não foi à toa que após sua filha e mãe irem embora no vagão, ao começar sua caminhada de volta para casa, desnorteado e triste, de repente parou, "em tanto que se esquisitou, parecia que ia perder o de si, parar de ser" (Rosa, 2008, p. 23).

Havia uma identificação e empatia por parte da comunidade com Sorôco, mesmo quando ele começa a cantar a canção da mãe e da filha que eram consideradas destoantes da norma. A canção é descrita como "um constado de enormes diversidades desta vida, que podiam doer na gente, sem jurisprudência de motivo nem lugar nenhum, mas pelo antes, pelo depois" (Rosa, 2008). Apesar de as personagens terem conseguido acessar algo em comum que tinham com todas as outras pessoas da comunidade por meio da música, gerando uma identificação mesmo que momentânea, não foi o suficiente para que fossem enxergadas com humanidade e, portanto, colaborassem para impedir o futuro terrível que as aguardava. No entanto, Sorôco sempre foi um indivíduo que não saía do controle, da norma social estabelecida por aquela sociedade. Helman (2006) explica que dentro de todas as sociedades existe um modelo das percepções comportamentais de um indivíduo. Mesmo um comportamento considerado anormal - desde que esteja sob algum controle - é compreendido e aceito pela comunidade. Sorôco havia acabado de perder sua família, estava em luto, logo, era compreensível e adequado que naquele momento quisesse relembrar de sua família, despertando na comunidade, ao invés de 
estranhamento (antes causado por sua mãe e filha), um sentimento de compaixão e empatia.

\section{Segundo conto: "A menina de lá"}

Em "A menina de lá", a personagem principal é uma criança com quase quatro anos chamada Maria, mas conhecida por todos como Nhinhinha. Ela sempre foi uma criança quieta e calada, não incomodava e nem mostrava preferência por nada. Os pais estranhavam seu comportamento, não a compreendiam. A menina gostava de observar a natureza, os animais, tinha sempre uma expressão calma e não se deixava afetar com nada. Até então estranhavam o comportamento da menina, mas nada faziam, até que começou a fazer "milagres" - ela fazia pedidos e eles, de maneira direta ou indireta, aconteciam. Os pais tentaram fazer que, por meio desse dom, ela os ajudasse em suas necessidades, porém Nhinhinha não atendia pelo pedido dos pais. Os pais e a personagem Tiantônia acreditavam que ela era uma "santa”, uma "milagreira”. A personagem difere das do conto anterior, pois é apresentada com um nome, características físicas específicas e o que talvez seja uma das principais diferenças: tem desejos. Um primeiro ponto a ser explorado é a questão da linguagem na infância. $\mathrm{O}$ autor ilustra no trecho seguinte como se expressava Nhinhinha e como era vista:

"Ninguém entende muita coisa que ela fala..." - dizia o Pai, com certo espanto. Menos pela estranhez das palavras, pois só em raro ela perguntava, por exemplo: - "Ele xurugou?" - e, vai ver, quem e o quê, jamais se saberia. Mas, pelo esquisito do juízo ou enfeitado do sentido. Com riso imprevisto: - "Tatu não vê a lua..." - ela falasse. Ou referia estórias, absurdas, vagas, tudo muito curto: da abelha que se voou para uma nuvem; de uma porção de meninas e meninos sentados a uma mesa de doces, comprida, comprida, por tempo que nem se acabava; ou da precisão de se fazer lista das coisas todas que no dia por dia a gente vem perdendo. Só a pura vida. (Rosa, 2008, p. 24-25)

Na infância é comum a fala diferenciada, que brinque com o significado das palavras durante o processo de aquisição de linguagem. A criança se comunica de forma bastante diferente. Para o adulto, "a concretude e a abstração já não têm o mesmo peso, pois é a razão que comumente domina o raciocínio" (Carnial, 2008). Telles (2014) afirma que a relação com o meio é o que induz a criança a se comunicar e desenvolver sua linguagem. E acrescenta:

Na articulação com a questão da infância, percebe-se que tradicionalmente ela é pensada como se não se relacionasse com o mundo, experienciando-o do seu modo - o que não ocorre da mesma forma que o adulto e nem da mesma forma que outra criança. Mas, ainda assim, há uma relação que não pode ser ignorada, muito menos padronizada. (Telles, 2014, p. 8)

Considerando que Nhinhinha mal tinha seus quatro anos completos, apesar de apresentar uma fala às vezes dificultosa e ser uma criança mais quieta, o que se apresentava em suas falas eram os elementos e vocabulário presentes no seu cotidiano, não eram tão distantes da realidade que vivia. Sobre isso o narrador-personagem diz: "O que falava, às vezes era comum, a gente é que ouvia exagerado" (Rosa, 2008, p. 26). Ainda assim, de acordo com a sua cultura familiar, a menina apresentava um comportamento peculiar, desviante na norma, que gerava estranhamento.

É importante pensar que o narrador-personagem e os outros que compõem a estória estão inscritos dentro de uma cultura, o que, por sua vez, faz com que vivenciem e enxerguem as situações moldadas em suas crenças e valores (Campos, 2017; Geertz, 1978; Helman, 2006; Kleinman, 1988; Langdon, Wiik, 2010; Oliveira, 2002). Logo, toda a estória é mediada pela "lente" dessa cultura. "Nunca mais vi Nhinhinha. Sei, porém, que foi por aí que ela começou a fazer milagres" (Rosa, 2008, p. 26). Esse trecho pode significar que a interpretação de "milagre" ao comportamento da criança de pedir e o pedido ser realizado representa a cultura daquela família. Como os antropólogos da saúde afirmam que acontece, isso mudou a forma com a qual Nhinhinha era vista e tratada. Antes disso ela era somente uma criança com atitudes estranhas e, depois que começou a "fazer milagres", passou a ser vista e tratada como uma divindade. 0 comportamento era considerado "anormal" naquele ambiente. No entanto, estava dentro do controle, pois acontecia 
em determinado contexto e havia uma explicação: ela era divina (Helman, 2006).

Apesar de estar incluída e ocupar lugar dentro dessa família, é necessário salientar que a personagem foi tirada de seu lugar de pessoa para passar a ser uma divindade. Kleinman (1988), sobre isso, diz dos diferentes recursos buscados pelas pessoas ao se defrontarem com as situações de doença ou daquilo que consideram comportamentos anormais. Nesse conto a família buscou, por meio de suas crenças e religiosidade, um significado que explicasse o comportamento que causava estranhamento. A família, nesse caso, não busca contato com o subsistema de saúde profissional, nem com o popular, como se observa no trecho: "Decidiram de guardar segredo. Não viessem ali os curiosos, gente maldosa e interesseira, com escândalos. Ou os padres, o bispo, quisessem tomar conta da menina, levá-la para sério convento. Ninguém, nem os parentes de mais perto, devia saber" (Rosa, 2008, p. 27); o primeiro e único a ser buscado foi o subsistema informal, ficando somente entre a família nuclear. Para além dessa leitura, o caso também pode representar o sistema popular de saúde, haja vista que os ditos "milagres" da “menina de lá" poderiam se colocar a serviço da comunidade, representando uma fonte de apoio e, eventualmente, de cura. Esses processos de cura e cuidado em saúde são valorizados e reconhecidos pelo grupo, constituindo um aspecto que confere credibilidade à menina e a coloca como referência na comunidade, como explorado na literatura sobre benzedeiras e curandeiras, por exemplo (Marin, Scorsolini-Comin, 2017), compondo um sistema de saúde próprio do lugar.

\section{Terceiro conto: "A terceira margem do rio"}

Em "A terceira margem do rio", o personagem principal, que vive com a esposa e seus filhos, sempre foi muito quieto, calado e levava uma vida sem grandes acontecimentos. Até que um dia decidiu encomendar uma canoa e, quando ela ficou pronta, sem sequer dar explicação, ele se despediu de todos, saiu de casa, entrou no rio com a canoa e nunca mais voltou. Durante o desenrolar da história muito se especulou sobre os motivos que o levaram a fazer isso e houve muitas tentativas de fazer que o pai saísse do rio e voltasse para casa, porém ele estava sempre alheio a qualquer movimento ou tentativa de comunicação que viesse de fora. 0 narrador, que é o filho desse homem, é quem nos relata, através das suas angústias e questionamentos, a história do pai, contando também a sua enquanto envelhece.

Desde o início do conto percebe-se que o pai apresentava comportamento muito quieto, misterioso, vivia em seus pensamentos, isolava-se mentalmente. Pensando no que Helman (2006) discute sobre normalidade e anormalidade, pode-se inferir que, apesar de apresentar um comportamento atípico, o pai agia de acordo com as normas, não se distanciava muito de um padrão de "normalidade", de modo que isso não era questionado nem problematizado por ninguém. A questão do isolamento mental do personagem fica mais evidente quando acontece de maneira física: o pai abandona sua família e rompe com qualquer convívio em sociedade, impossibilitando o contato com qualquer pessoa, para passar a viver sozinho sobre as águas do rio.

Nosso pai não voltou. Ele não tinha ido a nenhuma parte. Só executava a invenção de se permanecer naqueles espaços do rio, de meio a meio, sempre dentro da canoa, para dela não saltar, nunca mais. A estranheza dessa verdade deu para estarrecer de todo a gente. Aquilo que não havia, acontecia. Os parentes, vizinhos e conhecidos nossos, se reuniram, tomaram juntamente conselho. (Rosa, 20o8, p. 37)

O personagem deixou de agir de forma que até então era controlada pela sociedade, e passou agir fora desse controle estabelecido, causando um sentimento de "estranheza" em todos, produzindo em cada personagem uma série de significados diferentes para aquele comportamento. Ninguém queria julgálo "louco", o que pode nos dizer do lugar do "louco" naquela sociedade. O sentimento de vergonha apresentado pela esposa pode corroborar esse argumento. Para além do sentimento de vergonha, pode-se identificar também o sentimento de culpa, de responsabilidade dessa mulher, por entender que seria julgada pela sociedade caso tivesse um marido "doido", como se ela tivesse alguma causalidade ou responsabilidade nesse "diagnóstico". 
Nossa mãe, vergonhosa, se portou com muita cordura; por isso, todos pensaram de nosso pai a razão em que não queriam falar: doideira. Só uns achavam o entanto de poder também ser pagamento de promessa; ou que, nosso pai, quem sabe, por escrúpulo de estar com alguma feia doença, que seja, a lepra, se desertava para outra sina de existir, perto e longe de sua família dele. (Rosa, 2008, p. 37)

Outro ponto bastante evidente também nesse conto é como a atitude de isolamento do pai afetou cada personagem de sua família, em especial o filho, narrador da história. Esse aspecto pode ser visualizado no trecho a seguir:

A gente teve de se acostumar com aquilo. Às penas, que, com aquilo, a gente mesmo nunca se acostumou, em si, na verdade. Tiro por mim, que, no que queria, e no que não queria, só com nosso pai me achava: assunto que jogava para trás meus pensamentos. O severo que era, de não se entender, de maneira nenhuma, como ele aguentava. (Rosa, 2008, p. 39)

Existe a tentativa de aceitação, especialmente por parte do filho, que apresenta no texto a angústia de lidar com a perda do ideal de pai que tinha e de não conseguir compreender o motivo do comportamento dele: "Apertava o coração. Ele estava lá, sem a minha tranquilidade. Sou o culpado do que nem sei, de dor em aberto, no meu foro" (Rosa, 2008, p. 41). Os autores da antropologia da saúde colocam que cada indivíduo enxergará o comportamento do outro a partir das próprias crenças e sentimentos, a partir da sua própria lente, e isso gerava extrema angústia em todos, muita dificuldade e até certa impossibilidade em imaginar a alternativa de que talvez o pai pudesse estar, daquela maneira, vivendo sua existência em plenitude (Amadigi et al., 2009; Coelho, Almeida Filho, 2002; Geertz, 1998; Helman, 2006; Kleinman, 1988; Langdon, Wiik, 2010).

Em seu estudo sobre o conto, Scorsolini-Comin (2010) afirma que o filho acaba por participar da viagem do pai, como um colaborador em terra firme, o que gerou uma relação de dependência e estagnação nesse filho. Rosa (2008, p. 40) descreve essa relação estabelecida no trecho: "Eu fiquei aqui, de resto. Eu nunca podia querer me casar. Eu permaneci, com as bagagens da vida. Nosso pai carecia de mim, eu sei - na vagação, no rio no ermo - sem dar razão de seu feito”. Todos puderam seguir com suas vidas, mas não ele: "Sou homem de tristes palavras. De que era que eu tinha tanta, tanta culpa?" (Rosa, 2008, p. 41).

Scorsolini-Comin e Santos (2014) abordaram em seu estudo a questão da transmissão psíquica, explicando que, desde o nascimento, é transmitida ao sujeito uma herança familiar, com todas as suas crenças, tradições, seus comportamentos, modo de se relacionar afetivamente, representando para o indivíduo uma verdade inicial que permite sua inscrição como sujeito na história. No caso do filho, foi transmitido a ele, inconscientemente, seu papel, o modo de se relacionar com o pai e sua função dentro daquela família. Percebe-se, durante a estória, que esse lugar de cuidador foi um papel aos poucos ocupado por esse filho e também delegado por sua família, afinal todos sabiam que ele deixava comida para o pai, que o observava, se preocupava, mas não o impediam e nada diziam sobre isso. Isso pode estar relacionado ao seu sentimento de culpa, porque, inconscientemente, lhe foi legado que era seu papel cuidar do pai, e que este precisava dele. ScorsoliniComin e Santos (2014) falam sobre a importância de incorporar à análise os ciclos da vida familiar em todos os seus aspectos (mortes, nascimentos, enlaces), compreendendo como ocorrem os movimentos de passagem, elaboração e possível transformação do que precisa ser transmitido. É tarefa do indivíduo, na perspectiva da transmissão psíquica entre gerações, construir, organizar e transformar suas heranças psíquicas, elaborando-as para dotá-las de sentido. No caso desse filho, seria importante identificar essas heranças que lhes foram transmitidas para que pudesse se libertar dos sentimentos de responsabilidade e culpa, conseguindo seguir sua vida - e sua própria estória - como os outros fizeram. Essa análise destaca o grupo familiar enquanto coletivo no qual cravam-se compreensões sobre saúde e adoecimento, de modo que esses processos constituem não apenas os enredos dos personagens, mas também as decisões em saúde, os comportamentos sociais e os relacionamentos interpessoais que atravessam o isolamento, a vergonha, a culpa e as repercussões em saúde mental. 
Integração das narrativas de saúde, adoecimento e cuidado em Primeiras estórias

Os três contos apresentam pessoas em situações de "anormalidade" perante sua cultura, tendo as situações familiares como centro. A cultura irá desencadear em cada família e nos personagens uma repercussão como, no caso dos contos em tela, a exclusão, o adoecimento de um familiar, a incompreensão da diversidade das expressões da infância ou até a divinização do comportamento desviante.

Outro ponto apresentado pelos contos, mais especificamente o primeiro e o segundo, foi a desumanização dos personagens - Nhinhinha retratada como santa e a mãe e a filha de Sorôco como loucas. No terceiro conto, aborda-se o personagem de outra maneira: "Na nossa casa, a palavra doido não se falava, nunca mais se falou, os anos todos, não se condenava ninguém de doido. Ninguém é doido. Ou, então todos" (Rosa, 2008, p. 41). No entanto, o fato de não se falar na loucura pode ser interpretado como uma questão de medo do julgamento perante a sociedade. Os três contos demonstram, por parte da família e comunidade, o sentimento de incompreensão diante dos comportamentos considerados “anormais", sendo sempre vistos por uma ótica da cultura que os diferencia e distancia da condição humana. Como a loucura é ainda hoje marginalizada, apesar do advento da reforma psiquiátrica e seus desdobramentos (Castilho, Sant'anna, Alonso, 2017), é importante discutir e problematizar os conceitos de saúde e doença na área da saúde mental pela perspectiva da psiquiatria transcultural, assim como buscamos apresentar neste estudo.

Além dos aspectos aqui priorizados, é fundamental que se mantenha o diálogo da obra com uma característica essencial em Guimarães Rosa, que é a integração do romance com a vida pública e a abordagem de aspectos políticos e institucionais que atravessam essas dimensões (Roncari, 2004). Os elementos trazidos nos contos não podem ser reduzidos à compreensão de um cuidado individual e específico, mas a um modo de pensar cuidado, saúde e doença que remete a condições sociais que ultrapassam o limite da obra, ligando-se efetivamente à dimensão do público, conforme destaca Candido (2010). Recuperar os sentidos de saúde e doença nos contos não é apenas exercício de identificação e listagem de elementos para uma leitura interpretativa, mas um processo de compreensão acerca do modo como a obra se coloca, tanto como espelho de determinados valores sociais como provocadora de discussões que ultrapassam o espaço da arte em si, em direção ao vértice do público.

Guimarães Rosa, ao ser alçado como um "intérprete do Brasil" (Roncari, 2004, p. 20), possibilita uma leitura que também denuncia, em cenários regionais de exclusão, miséria, seca, fome e diversas agruras sociais, um modo de produzir sentidos sobre o adoecimento, ora visto como tragédia, ora como destino, ora como redenção. Esses sentidos não pertencem ou são endereçados ao autor em sua biografia pregressa como médico ou em seu viés político pela assunção de uma carreira diplomática, o que nos obrigaria a uma análise individual e na qual houvesse a exata correspondência entre autor e obra pelo viés da sublimação ou de uma leitura mais psicologizante (Leite, 2002). 0 movimento que se opera é o de justamente problematizar de que modo a produção do autor, aqui representada nas Primeiras estórias, carece cada vez mais de uma análise político-institucional que toque diversos marcadores sociais, como os de saúde, doença, cuidado, gênero, cor e regionalismos, por exemplo. Ampliar essa análise parece ser um desafio constante no campo de tensionamentos entre saúde e sociedade, aqui discutido.

As relações entre o artista (Guimarães Rosa) e o grupo (sociedade de referência) pautam-se na consideração de que os "elementos individuais adquirem significado social na medida em que as pessoas correspondem a necessidades coletivas; e estas, agindo, permitem por sua vez que os indivíduos possam exprimir-se, encontrando repercussão no grupo" (Candido, 2010, p. 35). As ressonâncias das Primeiras estórias atravessam também o modo como os processos de saúde e doença são interpretados nas práticas sociais. Adoecer, curar-se, submeter-se a um tratamento, explicar as causalidades e repercussões de determinado quadro orgânico, enfim, nos conduzem a reflexões que não se ancoram essencialmente na subjetividade de cada personagem como nos poderia sugerir uma análise mais individualizante, mas sim em uma rede de significados construídos 
coletivamente, quer seja na dimensão mais íntima da família, como no caso de "A terceira margem do rio", ou no universo social que aponta, recria, questiona e sustenta uma noção de saúde mental, no caso da mãe e da filha de Sorôco. Sustentar a relevância desse diálogo é também comprometer-se com uma discussão mais complexa que não cinde individual e coletivo, genético e cultural, saúde e doença, literatura e ciência, reafirmando os pressupostos que sustentam a noção de integralidade.

\section{Considerações finais}

A diversidade de conceitos de saúde e doença encontrados para os comportamentos considerados anormais varia de acordo com a cultura na qual o sujeito está inserido, e isso influencia diretamente na forma com que esses indivíduos serão tratados tanto pelas pessoas do seu ambiente familiar e de sua comunidade como pelos profissionais formais e informais. Além disso, moldará a maneira como os próprios sujeitos “anormais" expressarão, sentirão e vivenciarão os seus sintomas (Helman, 2006; Kleinman, 1988).

Com base no que foi analisado nos contos, percebese a existência de uma dificuldade em relação às formas de lidar com as questões de saúde mental, visto que isso gerou em cada conto desdobramentos diferentes, mas com pontos em comum. Observa-se em todos os contos o sentimento de angústia, incompreensão em alguns, até um olhar de desumanização para com o personagem, por parte da família e/ou comunidade, o que gerava comportamentos que muitas vezes podiam ser violentos, excludentes, negligentes, dependentes e mistificantes.

Por meio da antropologia da saúde e da psiquiatria transcultural percebeu-se a necessidade de analisar as questões de saúde mental, buscando compreender o sujeito de maneira holística, não reduzindo-o somente à sua cultura, nem somente aos seus sintomas biológicos, mas entendendo que ele é resultado de um todo que não pode ser separado. Haja vista que ainda hoje, no Brasil, persistem práticas violentas nos ambientes de cuidado da saúde mental e, mesmo com o advento da reforma psiquiátrica, nota-se a importância de buscar uma prática mais cuidadosa e humanizada, fugindo do modelo biomédico e da repetição dos erros já reportados no campo da saúde mental, em busca de leituras contemporâneas que efetivamente possam aventar mudanças e movimentos de aceitação, acolhimento e reinvenção. O diálogo com a literatura, como apresentado neste estudo, pode disparar reflexões importantes a esse desafio sempre premente.

\section{Referências}

ALMEIDA FILHO, N.; COELHO, M. T. A.; PERES, M. F. T. O conceito de saúde mental. Revista USP, São Paulo, v. 43, p. 100-125, 1999.

ALVES, D. G.; ASSIS, M. R. O desenvolvimento religioso e espiritual e a saúde mental: discutindo alguns de seus significados. Conexões Psi, Rio de Janeiro, v. 3, n. 1, p. 72-10o, 2015.

AMADIGI, F. R. et al. A antropologia como ferramenta para compreender as práticas de saúde nos diferentes contextos da vida humana. Revista Mineira de Enfermagem, Belo Horizonte, v. 13, n. 1, p. 131-138, 2009.

ARROYO, L. A cultura popular em Grande Sertão: Veredas. Rio de Janeiro: José Olympio, 1984.

BELO, F. R. R. Loucura e morte em "Sorôco, sua mãe, sua filha”, de João Guimarães Rosa. Boletim do CESP, Belo Horizonte, v. 19, n. 25, p. 109-120, 1999.

CAMPOS, E. Etnografia na pesquisa em saúde: alcoolismo, doença e significado em grupo de alcoólicos anônimos. Atas: Investigação Qualitativa em Ciências Sociais, [s.l.], n. 3, p. 537545, 2017.

CANDIDO, A. Literatura e sociedade. Rio de Janeiro: Ouro Sobre Azul, 2010, 204 p.

CARNIAL, L. A palavra transformadora em “A menina de lá”. Kalíope, São Paulo, v. 4, n. 2, p. 2530, 2008.

CASTILHO, A. F. A. N.; SANT'ANNA, C.; ALONSO, R. P. A supressão dos direitos humanos dentro do maior manicômio do estado brasileiro. Regrad: Revista Eletrônica de Graduação do Univem, Marília, v. 10, n. 1, p. 219-233, 2017.

COELHO, M. T. A. D.; ALMEIDA FILHO, N.

Conceitos de saúde em discursos contemporâneos 
de referência científica. História, Ciências, Saúde

- Manguinhos, Rio de Janeiro, v. 9, n. 2, p. 315-333, 2002.

COUTINHO, E. F. O idioma rosiano e o desafio de traduzi-lo. Scripta, Belo Horizonte, v. 2, n. 3, p. 8o88, 1998.

FOUCAULT, M. História da loucura: na idade clássica. 9. ed. São Paulo: Perspectiva, 2010.

GARCIA NETO, G. A.; TAURO, D. V. E. A psicose e saúde mental: impasses na contemporaneidade. Revista Psicologia e Saúde, Campo Grande, v. 7, n. 2, p. 152-16o, 2015.

GEERTZ, C. A interpretação das culturas. Rio de Janeiro: Zahar, 1978.

GOMES, N. S.; FARINA, M.; FORNO, C. D.

Espiritualidade, religiosidade e religião: reflexão de conceitos em artigos psicológicos. Revista de Psicologia da Imed, Passo Fundo, v. 6, n. 2, p. 107112, 2014.

HELMAN, C. G. Cultura, saúde e doença. 4. ed. Porto Alegre: Artmed, 2006.

KLEINMAN, A. Rethinking psychiatry. New York: The Free Press, 1988.

KLEINMAN, A.; EISENBERG, E.; GOOD, B. Culture, illness, and care: clinical lessons from anthropologic and cross-cultural research. Annals of Internal Medicine, Philadelphia, v. 88, n. 2, p. 251-258, 1978.

LANGDON, E. J.; WIIK, F. B. Antropologia, saúde e doença: uma introdução ao conceito de cultura aplicado às ciências da saúde. Revista LatinoAmericana de Enfermagem, Ribeirão Preto, v. 18, n. 3, 2010. Disponível em: <https://bit. ly/2LCvImJ >. Acesso em: 4 dez. 2017.

LEITE, D. M. Psicologia e literatura. 5. ed. São Paulo: Editora Unesp, 2002.

LEONEL, M. C. M. Guimarães Rosa alquimista: processos de criação do texto. 1985. Tese (Doutorado em Letras) - Universidade de São Paulo, São Paulo, 1985.

MARIN, R. C.; SCORSOLINI-COMIN, F. Desfazendo o "mau-olhado": magia, saúde e desenvolvimento no ofício das benzedeiras. Psicologia: Ciência e Profissão, Brasília, DF, v. 37, n. 2, p. 446-46o, 2017.

MARTINS, N. S. O léxico de Guimarães Rosa. São Paulo: Edusp, 2008.

MONTAGNA, V. R. F. "Desenredo” de Guimarães Rosa: descobertas de uma leitura. Revista Ide, São Paulo, v. 34, n. 52, p. 144-156, 2011.

NAKAMURA, E.; MARTIN, D.; SANTOS, J. F. Q. (Org.). Antropologia para enfermagem. Barueri: Manole, 2009.

OLIVEIRA, E. S. Guimarães Rosa e a figuração do trauma: leitura de hiato, de Tutameia. Reverso, Belo Horizonte, v. 37, n. 69, p. 61-68, 2015.

OLIVEIRA, F. A. Antropologia nos serviços de saúde: integralidade, cultura e comunicação. Interface, Botucatu, v. 6, n. 10, p. 63-74, 2002.

OLIVEIRA, F. J. A. Concepções de doença: o que os serviços de saúde têm a ver com isto? In: DUARTE, L. F. D.; LEA, O. F. (Org.). Doença, sofrimento, perturbação: perspectivas etnográficas. Rio de Janeiro: Fiocruz, 1998.

OLIVEIRA, M. R.; JUNGES, J. R. Saúde mental e espiritualidade/religiosidade: a visão de psicólogos. Estudos de Psicologia, Natal, v. 17, n. 3 , p. 469-476, 2012.

ROCHA, L. O. S. Guimarães Rosa e a medicina. Scripta, Belo Horizonte, v. 5, n. 10, p. 249-256, 2002.

RONCARI, L. O Brasil de Rosa: mito e história no universo rosiano: o amor e o poder. São Paulo: Editora Unesp, 2004.

ROSA, J. G. Primeiras estórias. Rio de Janeiro: MEDIAfashion, 2008.

SCLIAR, M. História do conceito de saúde. Physis: Revista de Saúde Coletiva, Rio de Janeiro, v. 17, n. 1, p. 29-41, 2007.

ROSENBAUM, Y. Notas sobre o conto "O espelho", de Guimarães Rosa. Revista Ide, São Paulo, v. 31, n. 47, p. $84-87,2008$.

SCORSOLINI-COMIN, F. A terceira margem do rio: algumas significações. Revista Querubim, Niterói, v. 6, n. 10, p. 34-40, 2010. 
SCORSOLINI-COMIN, F.; SANTOS, M. A. Família interdita: transgeracionalidade e subjetivação em três obras ficcionais. Psicologia em Estudo, Maringá, v. 17, n. 2, p. 255-266, 2012.

\section{SCORSOLINI-COMIN, F.; SANTOS, M. A. De} que substância é feito o amor? A construção da conjugalidade em Guimarães Rosa.

Subjetividades, Fortaleza, v. 14, n. 1, p. 17-28, 2014.
TELLES, T. C. B. A infância na fenomenologia de Merleau-Ponty: contribuições para a psicologia e para a educação. Revista do Nufen, Belém, v. 6, n. 2, p. 4-13, 2014.

VOLCAN, S. M. A. et al. Relação entre bem-estar espiritual e transtornos psiquiátricos menores: estudo transversal. Revista de Saúde Pública, São Paulo, v. 37, n. 4, p. 440-445, 2003.

\section{Contribuição dos autores}

Scorsolini-Comin foi responsável pela concepção do estudo e revisão do artigo. Ambos os autores contribuíram para a análise e escrita do manuscrito.

Recebido: 27/12/2017

Reapresentado: 06/04/2018

Aprovado: 02/07/2018 